\title{
Sentimentos vivenciados por mulheres frente ao diagnóstico de HIV/AIDS em um centro de referência sorológico
}

Feelings experienced by women in front of the diagnosis of HIV/AIDS in a serum of reference center

Sentimientos experimentados por mujeres frente al diagnóstico de VIH/SIDA en un suero de referencia centro

Luana Pereira Ibiapina Coêlho ORCID: https://orcid.org/0000-0002-2054-959X Faculdade de Venda Nova do Imigrante, Brasil E-mail: luana_ibiapina@hotmail.com

Kaio Germano Sousa da Silva ORCID: https://orcid.org/0000-0003-4236-6230 Centro Universitário de Ciências e Tecnologia do Maranhão, Brasil E-mail: kaiogsds@hotmail.com

Danielle Carvalho Rocha ORCID: https://orcid.org/0000-0002-4022-037X

Universidade Estadual do Maranhão, Brasil

E-mail: daniellerocha.slz@gmail.com Karine Costa Melo

ORCID: https://orcid.org/0000-0001-8253-859X

Universidade Federal do Maranhão, Brasil E-mail: karinemelo09@gmail.com Eduardo Brito da Silva

ORCID: https://orcid.org/0000-0002-8571-7806 Centro Universitário de Ciências e Tecnologia do Maranhão, Brasil E-mail: eduzinhobds@gmail.com

Francisca Thawanny de Souza Silva ORCID: https://orcid.org/0000-0003-2880-0985 Centro Universitário de Ciências e Tecnologia do Maranhão, Brasil

E-mail: kaiogermano123890@gmail.com

Sostenise Maciel de Azevedo ORCID: https://orcid.org/0000-0002-4731-8337 Universidade Estadual do Maranhão, Brasil

E-mail: sostenisemaciel@gmail.com

Jesica Cristina Lira dos Santos

ORCID: https://orcid.org/0000-0003-1902-585X

Universidade Estadual do Maranhão, Brasil E-mail: jecristinalira@gmail.com

Ana Carolina Feitosa Chaves

ORCID: https://orcos.org/0000-0002-0309-5354

Universidade Estadual do Maranhão, Brasil E-mail: ac.feitosa@outlook.com

Polyana Cabral da Silva

ORCID: https://orcid.org/0000-0003-2626-5181

Universidade Estadual do Maranhão, Brasil

E-mail: enf.polyanacabral@hotmail.com

Pedro Vitor Mendes Santos

ORCID: https://orcid.org/0000-0002-2249-1440

Universidade Estadual do Maranhão, Brasil

E-mail: pedrovitorp2@hotmail.com

Leiliane Barbosa de Aguiar

ORCID: https://orcid.org/0000-0001-7134-049X

Centro Universitário de Ciências e Tecnologia do Maranhão, Brasil

E-mail: leilianeaguiarcxs@gmail.com

Pedro Henrique Medeiros de Andrade

ORCID: https://orcid.org/0000-0003-1819-9540

Centro Universitário de Ciências e Tecnologia do Maranhão, Brasil E-mail: pedro.medeiroscx@gmail.com 


\author{
Luzivania de Jesus Oliveira \\ ORCID: https://orcid.org/0000-0002-4365-1407 \\ Faculdade Laboro, Brasi \\ E-mail: luhdj_12@hotmail.com \\ Amanda Kauany Pereira da Silva \\ ORCID: https://orcid.org/0000-0003-3317-1570 \\ Faculdade Tecnológica de Educação Superior, Brasil \\ E-mail: kauanyamanda003@gmail.com \\ Yohanna Larissa Soares Damasceno \\ ORCID: https://orcid.org/0000-0001-8358-7844 \\ Centro Universitário de Ciências e Tecnologia do Maranhão, Brasil \\ E-mail: hannalara_611@ @otmail.com
}

\begin{abstract}
Resumo
As Doenças Sexualmente Transmissíveis (DSTs) têm se tornado cada vez mais frequentes em todo o mundo, por isso se tornaram um grande problema de Saúde Pública. O estudo teve como objetivo descrever os sentimentos vivenciados por mulheres frente ao diagnóstico de HIV/AIDS em um Centro de Referência Sorológico. Tratou-se de uma pesquisa de abordagem qualitativa, de natureza exploratória, descritiva e explicativa. Quanto aos principais resultados, observou-se a descoberta do diagnóstico do HIV/AIDS se configura como um momento de transição na vida da pessoa. Desorganiza o ser, as relações e a vida em sociedade, principalmente entre os mais próximos, como família e amigos. Esse momento também é acompanhado de incertezas, ansiedade, insegurança, medo de situação desconhecida e assustadora. Portanto, no confronto com a nova realidade, a pessoa vivencia momentos de sofrimento. Conclui-se que as mulheres que convivem com o vírus HIV enfrentaram situações divergentes e conflitantes ao receber o diagnóstico soropositivo para aprender a viver com essa nova realidade.
\end{abstract}

Palavras-chave: Doenças sexualmente transmissíveis; Emoções; Autoimagem.

\begin{abstract}
Sexually Transmitted Diseases (STDs) have become increasingly frequent worldwide, so they have become a major public health problem. The study aimed to describe the feelings experienced by women regarding the diagnosis of HIV / AIDS in a Serological Reference Center. It was a qualitative, exploratory, descriptive and explanatory research. As for the main results, the discovery of the HIV / AIDS diagnosis was seen as a moment of transition in the person's life. It disorganizes being, relationships and life in society, especially among those closest to us, such as family and friends. This moment is also accompanied by uncertainty, anxiety, insecurity, fear of an unknown and frightening situation. Therefore, in the confrontation with the new reality, the person experiences moments of suffering. It is concluded that women who live with the HIV virus faced divergent and conflicting situations when receiving the seropositive diagnosis to learn to live with this new reality.
\end{abstract}

Keywords: Sexually transmitted diseases; Emotions; Self concept.

\title{
Resumen
}

Las Enfermedades de Transmisión Sexual (ETS) se han vuelto cada vez más frecuentes en todo el mundo, por eso se han convertido en un importante problema de salud pública. El estudio tuvo como objetivo describir los sentimientos que experimentan las mujeres con respecto al diagnóstico de VIH / SIDA en un Centro de Referencia Serológica. Fue una investigación cualitativa, exploratoria, descriptiva y explicativa. En cuanto a los principales resultados, se observó que el descubrimiento del diagnóstico de VIH / SIDA se configura como un momento de transición en la vida de la persona. Desorganiza el ser, las relaciones y la vida en sociedad, especialmente entre los más cercanos a ellos, como familiares y amigos. Este momento también va acompañado de incertidumbre, ansiedad, inseguridad, miedo a una situación desconocida y aterradora. Por tanto, cuando se enfrenta a la nueva realidad, la persona experimenta momentos de sufrimiento. Se concluye que las mujeres viviendo con el virus del VIH enfrentaron situaciones divergentes y conflictivas al recibir el diagnóstico de seropositivo para aprender a vivir con esta nueva realidad.

Palabras clave: Enfermedades de transmisión sexual; Emociones; Auto imagen.

\section{Introdução}

As Doenças Sexualmente Transmissíveis (DSTs) têm se tornado cada vez mais frequentes em todo o mundo, por isso se tornaram um grande problema de Saúde Pública. Despertando sensações e sentimentos negativos em seus portadores e ainda, elevados custos para a economia do país, necessitando, assim, de uma atenção maior por parte dos governos (Agostini, Rocha, Melo \& Maksudi, 2019).

As DSTs estão mais próximas do contexto vivencial das pessoas evidenciando uma modificação do comportamento humano no que se refere ao seu limite, a abertura precoce à vida sexual, a multiplicidade de parceiros sexuais, o conflito de 
confiança entre casais, enfraquecida em virtude da promiscuidade, do diálogo restrito e da desestruturação familiar. Aspectos que contribuem para o avanço de doenças como a Síndrome da Imunodeficiência Adquirida (AIDS) (Nascimento, Silva, Martins, Nunes, \&Cerqueira, 2010).

O HIV é um retrovírus que enfraquece as defesas imunitárias do corpo destruindo os linfócitos CD4 (células - T). Estes linfócitos CD4 constituem um grupo de células brancas do sangue que normalmente ajudam o organismo a defender-se contra os ataques das bactérias, vírus e outros germes através da coordenação do sistema imunológico. Quando o HIV destrói os linfócitos CD4, o corpo torna-se vulnerável a diversos tipos de infecções oportunistas, ou seja, infecções que têm a oportunidade de invadir o corpo humano porque as defesas imunitárias estão enfraquecidas (Lourenço \& Afonso, 2009).

Onde a descoberta da soropositividade é traumática, representando para o indivíduo um grande abalo emocional para algumas pessoas, ao se defrontarem com o diagnóstico de uma síndrome que ainda não oferece possibilidade de cura, se desestruturam emocionalmente (Cechim \& Selli, 2007). O impacto da notícia do diagnóstico positivo e a convivência com HIV, às vezes, é carregado e permeado de sentimentos tão intensos e angustiantes que o desejo de morte se faz presente (Serra, Sardinha, Pereira \& lima, 2013).

Rabuske (2009) expõe que a comunicação do diagnóstico é uma tarefa difícil, considerando-se a gravidade da doença e o comprometimento do prognóstico. Doenças como câncer e AIDS têm uma carga simbólica muito grande e são ouvidas como sentenças de morte ou remetem a sua proximidade, o que contribui para dificultar a revelação do diagnóstico de ambas às doenças.

Diante do exposto, pode-se perceber que a existência de estigmas em relação às pessoas soropositivas exerce grande peso em suas vidas, e um sentimento de morte anunciada surge em correlação mediante diagnóstico positivo ao HIV/AIDS. Assim, após leitura aprofundada a respeito do tema proposto, desenvolveu-se a seguinte problemática: Quais os sentimentos que as mulheres soropositivas ao HIV/AIDS vivenciam mediante diagnóstico de sua doença? Para tal, objetivou-se descrever os sentimentos vivenciados por mulheres frente ao diagnóstico de HIV/AIDS em um Centro de Referência Sorológico.

A escolha do tema surgiu após estágio supervisionado da disciplina de Moléstias Infecciosas em um Centro de Testagem e Aconselhamento ao paciente portador de HIV/AIDS na cidade de Parnaíba-PI. Surgindo da necessidade de promover uma reflexão e discussão sobre essa temática, devido às dificuldades dos seres humanos em lidar com esse evento.

Esta pesquisa tornou-se relevante por mostrar os sentimentos vivenciados pelas mulheres frente ao diagnóstico de HIV/AIDS na visão das próprias portadoras, com a expectativa de que os resultados possam ser úteis para uma melhor compreensão sobre os sentimentos vividos pelas entrevistadas, contribuindo para buscar subsídios norteadores para uma assistência de enfermagem qualificada e integral.

\section{Metodologia}

Trata-se de uma pesquisa de abordagem qualitativa, de natureza exploratória, descritiva e explicativa. Nos estudos de abordagem qualitativa, os investigadores determinam estratégias e procedimentos que lhe permitam tomar em consideração as experiências sob a ótica do entrevistado. A investigação qualitativa deve refletir uma espécie de diálogo entre investigadores e os respectivos sujeitos participantes da pesquisa (Dyniewicz, 2007).

Para Gil (2006), a pesquisa exploratória tem como finalidade proporcionar maiores informações acerca de determinado assunto e facilitar a delimitação de um tema de trabalho. Geralmente constitui a primeira etapa de uma investigação mais ampla e desenvolve-se com o objetivo de proporcionar uma visão geral, de tipo aproximado, acerca de determinado fato.

Na pesquisa descritiva, o pesquisador busca maior familiaridade com o problema, com vistas a torná-lo mais explícito ou a constituir hipóteses, bem como estudar a característica de um grupo ou fenômeno, estabelecendo relações entre variáveis e 
por vezes determinando a natureza destas relações (Gil, 2010).

A pesquisa explicativa tem como objetivo central, identificar os fatores determinantes para a ocorrência de determinados fenômenos. É o tipo de pesquisa que mais aprofunda o conhecimento da realidade, já que explica as razões das coisas. É também uma pesquisa bastante complexa e delicada devido às maiores possibilidades de erros (Gil, 2006).

O presente estudo foi realizado em um Centro Público Municipal de Referência Sorológico do Município de ParnaíbaPI que está localizado na Região Norte do Estado do Piauí e distando 339 km da Capital Teresina. Segundo o IBGE (2010), o Município possui uma população de 145.705 habitantes, predominando o sexo feminino, unidade territorial de 435, $573 \mathrm{~km} 2$ e densidade demográfica de $334,51 \mathrm{hab} / \mathrm{km}^{2}$.

O referido Centro Sorológico é referência em atendimento na região, além de cidades vizinhas dos Estados do Ceará e Maranhão. Nele estão cadastrados aproximadamente 180 pacientes portadores de HIV/AIDS, prestando ainda atendimento médico a cidadãos acometidos de outras doenças sexualmente transmissíveis como sífilis, clamídia, gonorreia, herpes e vírus do papiloma humano (HPV), além de agravos como hepatites virais. O serviço apresenta equipe multiprofissional composta por: médico infectologista, enfermeiro, técnico de enfermagem, assistente social e psicólogo.

Os sujeitos participantes da pesquisa foram dez mulheres que faziam tratamento há mais de um ano no Centro de Testagem e Aconselhamento, na faixa etária de 20 a 59 anos e residentes em Parnaíba-PI. Os critérios de exclusão foram pacientes com período inferior a um ano de tratamento, pacientes do sexo masculino, e idade inferior a 18 anos.

A coleta de dados foi realizada através de uma amostragem aleatória simples, após aprovação do Comitê de Ética em Pesquisa da Universidade Estadual do Piauí- UESPI por meio de uma entrevista semi-estruturada que ocorreu no mês de abril do ano de 2014; na ocasião em que as pacientes aguardavam atendimento médico foi realizado pelas enfermeiras de plantão um contato inicial com as pacientes para explicar o objetivo do trabalho, e havendo o interesse pela participação na pesquisa, elas foram encaminhadas para uma sala reservada para serem entrevistadas.

Visto que, o pesquisador foi o responsável por cumprir todas as normas que são preestabelecidas na Resolução CNS $n^{\circ}$ 466/12, que dar disposições sobre a proteção aos participantes de pesquisas científicas que envolvem seres humanos, sob o $\mathrm{n}^{\circ}$ de Certificado de Apresentação para Apreciação Ética (CAAE) nº 26346713.8.0000.5209.

De modo geral, a pesquisa não ofereceu altos riscos aos participantes, onde, eventualmente, poderia ocasionar fragilização mental, podendo gerar estresse e ansiedade. Neste ponto, a entrevista deveria ser interrompida e o participante poderia ser retirar ou ser encaminhado para o atendimento psicológico do município, onde a entrevista poderia ser remarcada ou abandonada a qualquer momento. Para minimizar os riscos, os pesquisadores se comprometeram a assumir a responsabilidade de prestar assistência integral a qualquer problema que viesse a surgir em decorrência do estudo.

Quanto aos benefícios, é notado que esses são maiores em comparação aos riscos, no qual a realização da pesquisa possibilitará a aquisição de conhecimento científico sobre a temática, desta forma, trazendo um olhar sensível e humanizado ao tratamento de pacientes com HIV/AIDS tanto físico quanto psicológico. Outro benefício do estudo é o aprofundamento dos conhecimentos teóricos sobre a abordagem multidisciplinar no cuidado ao paciente, ajudando-o a enfrentar suas limitações, e auxiliar no processo de autoaceitação.

De acordo com Minayo (2007) a entrevista é, sobretudo, uma conversa a dois, ou entre vários interlocutores, realizada por iniciativa de um entrevistador. Tem por objetivo construir informações pertinentes para um objeto de pesquisa, e abordagem pelo entrevistador, de temas igualmente pertinentes com vistas a este objetivo. A entrevista semi-estruturada reúne perguntas abertas e fechadas, onde o entrevistado tem a disponibilidade de discorrer sobre um tema sem ficar restrito ao questionamento formulado.

Para auxiliar o momento da entrevista, foi utilizado um roteiro semi-estruturado elaborado pela autora do projeto que envolvia duas partes: a primeira contendo dados pessoais e a segunda contendo perguntas abertas que permitiram compreender 
a percepção dos sujeitos sobre o objeto pesquisado. As entrevistas foram realizadas individualmente em um local que privilegiou a privacidade das mulheres e favoreceu a interlocução entre pesquisadora e entrevistada. Foi solicitada a permissão do uso de um gravador como instrumento de auxílio, tendo em vista facilitar o registro integral de suas falas e posterior transcrição.

A análise dos dados se deu a partir dos discursos das participantes, em que as informações colhidas foram agrupadas em categorias de significados e submetidas à análise do conteúdo, visando abstrair os significados mais relevantes das falas em estudo e levando em consideração referencial teóricos da temática abordada.

A análise de conteúdo propõe técnicas que auxiliam no processo de fragmentar e reagrupar as falas e pensamentos dos entrevistados. Empregar-se-á a técnica de análise categorial por esta conseguir reunir diversos pensamentos e ideias (unidades de registro ou temas) em grupos maiores (categorias), considerando-se as afinidades e disparidades entre os temas e dependendo dos critérios de classificação, do que se procura e o que se espera encontrar (Bardin, 2004).

Todos os sujeitos deveriam ser inicialmente informados sobre o objetivo e relevância do estudo, e caso aceitassem participar da pesquisa, deveriam assinar o Termo de Consentimento Livre e Esclarecido em conformidade com a Resolução 466/12 do Conselho Nacional de Saúde, o qual foi assinado ou colocado a digital em duas vias de igual teor, ficando uma via em poder da participante e outra com a autora da pesquisa.

Foram escolhidos pseudônimos de forma aleatória, a fim de manter e garantir o anonimato das participantes da pesquisa. A identificação dessas participantes não será revelada, mesmo quando os resultados desta pesquisa forem divulgados de qualquer forma.

\section{Resultados e Discussão}

A apresentação dos resultados e discussão foi separada em duas etapas: No qual a primeira refere-se à caracterização das mulheres que participaram da pesquisa, e a segunda diz respeito ao cumprimento dos objetivos do estudo, utilizando-se da exposição e análise das falas das entrevistadas.

\section{Caracterização dos sujeitos}

A análise do perfil das dez entrevistadas revelou que a maioria tinha idade variando de 34 a 39 anos, sendo três solteiras e sete casadas. Quanto ao nível de escolaridade, nove possuíam ensino fundamental incompleto e apenas uma com ensino superior incompleto. Quanto à religião, seis eram católicas e quatro eram evangélicas. Quanto à ocupação, oito eram domésticas, uma vendedora autônoma e uma estudante. Em relação às etnias, sete participantes eram pardas, duas brancas e uma negra. Quando interrogadas de como souberam da existência do Centro de Testagem e Aconselhamento, sete das participantes expuseram que haviam ficado sabendo através de encaminhamento médico, duas através de amigos e uma através do parceiro.

\section{As classes e suas descrições}

As informações foram obtidas por meio de entrevistas com mulheres que frequentavam o Centro Público Municipal de Referência Sorológico do Município de Parnaíba-PI, onde os dados relacionados ao estudo foram expostos mediante as falas das participantes, com total garantia de anonimato, para isso, as mulheres foram identificadas apenas com o nome "Entrevistada" e por números que designaram a ordem na qual as entrevistas foram realizadas (Entrevistada 1, Entrevistada 2, Entrevistada 3...).

A análise dos dados foi constituída de cinco classes: Classe 1 - Conhecimento sobre HIV/AIDS antes do diagnóstico;

Classe 2 - Autopercepção de vulnerabilidade e circunstâncias em que as mesmas contraíram o vírus; Classe 3 - Sentimentos 
vivenciados durante o diagnóstico de soropositividade; Classe 4 - O sentimento de culpa gerado pela presença da doença; Classe 5 - A modificação que a doença causou em sua vida. As classes estão expostas a seguir descrevendo os principais resultados da pesquisa.

\section{Classe 1. Conhecimento sobre HIV/AIDS antes do diagnóstico}

Quando questionadas sobre o acesso a informações da doença antes do diagnóstico, identificou-se que grande parte das entrevistadas citou ter ouvido falar sobre a doença, mas que não sabiam das formas de transmissão do vírus. A minoria citou que tinha conhecimento sobre a doença e que por ter conhecimento adotava medidas protetoras, como ficaram evidenciados nas falas a seguir:

"Sabia, as pessoas já tinham me informado, mas eu nunca pensei que eu pudesse né? Que eu tinha, que eu ia ter também. Depois que pegamos que elas foram informar como pegava né? Que é através de relação sem camisinha, eu não sabia que pegava." (ENTREVISTADA 03)

"Não, não sabia, só sabia que tinha HIV/AIDS, mas eu não sabia como era que era, como era que não era. Só sabia que existia a doença." (ENTREVISTADA 05)

"Essa palavra pra mim AIDS, essa palavra quando eu ouvia falar eu tinha medo, eu sabia como pegava, que tinha que se prevenir usando preservativo, e não só, tipo assim um vacilo, é segus, segus diferente, anal, é como falavam, na boca, isso tudo corre o risco também da gente pegar." (ENTREVISTADA 06)

Pelo exposto acima, é possível perceber que a maioria das entrevistadas citou que tinham conhecimento sobre a doença, podendo-se perceber papel relevante no que se refere à influência na adoção de medidas protetoras. $\mathrm{O}$ não conhecimento sobre a doença também foi citado, mostrando uma preocupante proporção e não deixando de excluir a necessidade de uma abordagem contínua sobre o tema em questão.

A falta do conhecimento sobre a doença é bastante relevante; mostrando, assim, a importância da necessidade de ações de promoção à saúde que visem à apropriação de conhecimentos mais efetivos sobre HIV/AIDS e de como exercer a sexualidade de forma responsável, contribuindo com a diminuição das taxas de transmissão.

Em um estudo que procurava detectar o conhecimento de mulheres soropositivas sobre a transmissão e a prevenção do HIV, Gir et al. (2004) ao questionar o conhecimento dessas mulheres, detectou que $62 \%$ referiram desconhecer os mecanismos de transmissão do HIV e $68 \%$ desconheciam as medidas preventivas. Confirmando, assim, que os níveis de desconhecimento sobre a patologia em questão ainda se encontram elevados (Guimarães et al., 2019).

Embora um bom conhecimento não seja suficiente para a adoção de medidas de prevenção, informações precisas e específicas sobre o HIV/ AIDS podem beneficiar a saúde sexual, impactando nas atitudes que promovam a saúde e o bemestar. Neste sentido, é necessário que políticas públicas sejam implementadas, permitindo monitorar e avaliar o conhecimento sobre o HIV/AIDS nesta e em outras populações-chave em suas dimensões social, individual e estrutural (Gomes, Cecccato, Rocha, \& Guimarães, 2013).

\section{Classe 2. Autopercepção de vulnerabilidade e circunstâncias em que as mesmas contraíram o vírus}

Quando indagadas sobre o próprio risco em contrair o HIV/AIDS, não houve diferença de argumento entre as depoentes do estudo. Demonstrando que todas as mulheres entrevistadas não se achavam vulneráveis ao HIV/AIDS, uma vez que colocam a redução da vulnerabilidade na confiança depositada no outro, seja ele parceiro, no caso das entrevistadas solteiras, seja ele marido, no caso das entrevistadas casadas. Esses relatos vão de desencontro com a realidade, uma vez que 
todas as entrevistadas vieram a contrair o vírus através de relação com o parceiro ou com o marido, como ficaram evidenciados nos relatos abaixo:

\author{
“Através de relação com meu marido (...) Não, porque eu confiava nele." (ENTREVISTADA 07) \\ "Eu peguei do pai da minha filha, eu pensei que ele era fiel a mim e não era, e acabou que ele pegou de outra pessoa \\ e passou pra mim (...) Confiava no meu marido e não me via vulnerável." (ENTREVISTADA 09) \\ "Relação sexual com meu parceiro, ele tinha outra pessoa e eu não sabia, pegou dela e passou pra mim (...) Eu usava \\ o preservativo as vezes, eu não esperava isso, mas todo cuidado é pouco" (ENTREVISTADA 10)
}

Os recortes das entrevistas acima mostram que a credibilidade no amor e no casamento, no ponto de vista das entrevistadas, constitui uma barreira importante na redução da vulnerabilidade ao HIV/AIDS. Esse entendimento foi observado no estudo de Oltramari e Otto (2006) que, nas relações estáveis, onde existe confiança entre os parceiros, o uso do preservativo passa a ser julgado desnecessário. Por se sentirem seguros em relação ao risco de infecção pelo HIV, o estudo indica também a perpetuação da concepção de grupo de risco, fazendo-os acreditar, consequentemente, que estão imunes à contaminação pelo HIV.

Sousa e Barroso (2009) esclarecem que, antes do diagnóstico soropositivo, o casal mantém um relacionamento sexual em que a prática da prevenção é geralmente inexistente devido a dois fatores principais: a não adesão do preservativo pelo homem e à falta de voz ativa da mulher para negociar seu uso. Inserida nesta relação de poder, a mulher acaba abrindo mão de opor-se aos comportamentos do parceiro e, muitas vezes, atribui, apenas a ele, a responsabilidade de prevenção. Além disso, a mulher não se identifica como alguém que apresenta um comportamento de risco, na medida em que se encontra em um relacionamento estável, possuindo a fantasia de que não está vulnerável à infecção.

Nessa perspectiva, Aboim (2012) sublinha que o fato de um indivíduo perceber que está em risco de se infectar, seja pelo vírus HIV ou qualquer outra doença sexualmente transmissível, parece não direcioná-lo linearmente ao uso do preservativo. E assinala que são as mulheres de perfil monogâmico e envolvidas em relacionamentos conjugais são as que menos se previnem contra eventuais riscos de transmissão.

Ayres (2004) diz que as condições que afetam a vulnerabilidade individual são de ordem cognitiva (informação, consciência do problema e das formas de enfrentá-lo), comportamentais (interesse e habilidade para transformar atitudes e ações a partir daqueles elementos cognitivos) e sociais (acesso a recursos e poder para adotar comportamentos protetores).

Todavia, Serra et al. (2013) lembram que, apesar de se ter ciência de que, no caso da AIDS, o grau de informação que um indivíduo possui sobre formas de transmissão e situações de risco não é suficiente para que passe a adotar um comportamento protetor, a falta de informações básicas contribui para aumentar sua vulnerabilidade.

\title{
Classe 3. Sentimentos vivenciados durante o diagnóstico de soropositividade
}

Receber o diagnóstico de uma doença ainda sem cura gera vários sentimentos negativos. Quando questionadas sobre os sentimentos vivenciados durante o diagnóstico soropositivo, foi possível detectar que quase todas as entrevistadas se desestruturaram emocionalmente mediante o diagnóstico, no entanto, teve quem se mostrou calma com a notícia.

"Foi meio que desesperador, eu entrei em estado meio que de choque, eu acreditava, sabia, mas num caia a ficha que eu tinha, no começo é meio difícil. Depois você vai se acostumando, ver que não é, é difícil né? Mas depois você ver que pode viver sua vida normalmente, só se cuidar, se tratar e se prevenir." (ENTREVISTADA 02)

"Eu fiquei assim mesmo calma, tranquila, fiquei desesperada não, não fiquei aperriada." (ENTREVISTADA 04) 
"Eu chorei muito, quis me matar, eu não aceitava, tava com essa doença, vou durar quantos meses? Eu não aceitava." (ENTREVISTADA 06)

"Foi um choque, choque muito grande, até hoje eu to tipo traumatizada, eu era uma pessoa alegre, não me abatia, mas por eu imaginar que eu me prevenia tanto e chegar ao caso de eu fazer o exame e dar positivo." (ENTREVISTADA 10)

Por meio das falas das mulheres pesquisadas, percebeu-se a interferência da soropositividade na sua vida; que para algumas, o HIV/AIDS aparecia de forma negativa, doença que mata; e para outras, embora reconhecendo esses aspectos negativos do HIV/AIDS, foi notável que estão cientes de que seguindo o tratamento e todas as recomendações médicas podem ter um longo período de vida; por outro lado, verificou-se resistência apenas de uma das mulheres entrevistadas ao enfrentamento dessa situação.

A fala das entrevistadas acima reforça o resultado dos estudos de Moreno e Reis (2013), em sua pesquisa realizada com 14 sujeitos em dois Centros de Testagem e Aconselhamento em DST/AIDS de São Paulo sobre os sentimentos vivenciados diante do diagnóstico soropositivo, verificou-se que apenas uma pessoa aceitou sua soropositividade, acreditando que não seria negado pela sociedade, já o restante da amostra relatou sentimentos como medo, abandono e negação da doença.

Barbosa e Ramalho (2007) comentam, em sua pesquisa, que procurou investigar acerca da influência do diagnóstico positivo na vida de mulheres usuárias do Serviço de Assistência Especializada (SAE) do município de Campina Grande (PB) realizado com oito usuários do referido serviço, quando questionadas sobre a reação após saberem da sua condição de soropositivo, todas as entrevistadas demonstraram um sentimento negativo, como se o mundo e a vida, em torno de si, tivessem se destruído.

Ayres et al. (2004) afirmam que o diagnóstico da AIDS representa um evento catastrófico, por estar associado a uma evolução clínica de rápida deterioração, além de não se dispor de qualquer tratamento curativo e de apresentar um prognóstico extremamente ruim.

A descoberta do diagnóstico do HIV/AIDS se configura como um momento de transição na vida da pessoa. Desorganiza o ser, as relações e a vida em sociedade, principalmente entre os mais próximos, como família e amigos. Esse momento também é acompanhado de incertezas, ansiedade, insegurança, medo de situação desconhecida e assustadora. Portanto, no confronto com a nova realidade, a pessoa vivencia momentos de sofrimento (Almeida \& Labrocini, 2007).

\section{Classe 4. O sentimento de culpa gerado pela presença da doença}

Quando indagadas se elas culpavam alguém pelo fato da soropositividade, perceberam-se disparidades nos relatos quanto a quem culpar: algumas entrevistadas atribuíram a culpa ao parceiro ou marido; por outro lado, algumas culparam o parceiro ou marido apenas no começo do diagnóstico positivo e outras culparam a si mesmas.

O sentimento de culpa ocasionado diante do resultado soropositivo pode despertar diversos sentimentos negativos nas mulheres, sentimentos esses que podem vir a interferir na relação amorosa ou até mesmo no desenvolvimento de distúrbios como a depressão.

“Eu culpo a pessoa que tava comigo né? Eu não sabia que ele tinha a doença." (ENTREVISTADA 01)

"No começo eu culpo, culpava ele muito, mas a vezes quando bate uma "deprê" assim aí eu culpo ele, mas como ele não sabia também, não sei se ele sabia, é complicado cara, muito complicado. Tu não sabe a quem culpar, não sabe se se culpa, não sabe se culpa ele." (ENTREVISTADA 02)

“Culpo a mim mesmo, porque assim, não porque eu não me prevenia, assim, aliás, eu me prevenia, mas assim eu culpo, porque eu tinha algumas coisas na vida pra ter um futuro diferente e escolhi um caminho que não era pra mim, eu acho, eu me culpo." (ENTREVISTADA 06) 
Como foi visto nas respostas das entrevistadas acima, pôde-se detectar que as depoentes descreveram que o viver com HIV/AIDS pode vir acompanhado pela presença de sentimento de culpa que acompanham o cotidiano dessas pessoas acarretando avaliações negativas em sua qualidade de vida.

Estudos de Gomes, Silva e Oliveira (2011) realizado com 30 indivíduos soropositivos em acompanhamento ambulatorial de um hospital público municipal, localizado na cidade do Rio de Janeiro, os sujeitos declararam que, algumas vezes, adotaram comportamento sexual comprometedor, que culminou em sua soropositividade, demonstrando forte sentimento de culpa.

De acordo com Collins (1905), a culpa se encontra presente em todas as dimensões da vida humana, podendo se relacionar tanto a questões psicossociais, como aspectos estruturais e mais gerais; aspectos que podem se relacionar com os resultados presentes, tendo em vista que a falta de cuidados a saúde, escassez de informações, de recursos financeiros, pode ser relacionadas com sentimento de culpa entre os pacientes soropositivos.

Em decorrência das falas das entrevistadas e dos autores com suas teorias, percebeu-se que as mulheres vivenciam reações emocionais negativas. Por isso, é relevante a importância da equipe multiprofissional dos Centros de Testagem e Aconselhamento no apoio a essas mulheres, buscando atenuar os sentimentos, confortando e passando segurança para elas, para assim, proporcionar uma melhor forma de enfrentamento da doença.

\title{
Classe 5. A modificação que a doença causou em sua vida
}

Quando indagadas sobre a alteração desencadeada pela presença do vírus em sua vida, no intuito de procurar saber de que modo à doença repercutiu na sua qualidade de vida, os sentimentos de tristeza, exclusão e desprezo foram relatados nas falas de algumas depoentes, no entanto, pôde-se perceber também que com o passar do tempo algumas entrevistadas afirmaram que se adaptaram e aprenderam a conviver com a doença e, com isso, a percepção da qualidade de vida foi melhorando, como ficou evidente nos relatos a seguir:

\begin{abstract}
"Ah, pra ser sincera tem dia até que eu penso que não tenho nem isso, eu não me abalei não, vivo normal, eu trabalho em casa de família, só que as pessoas não sabem, porque não digo pras pessoas, só quem sabe nós tem esse problema é a família dele, porque minha mãe mora no Cajueiro da Praia e ela não sabe, meus familiares, eu não tive coragem de contar pra ela. Eu fico é pensando nas crianças o povo ficar falando: Ah! os pais deles tem isso. Eu prefiro não contar." (ENTREVISTADA 03)
\end{abstract}

"Triste, triste, porque eu não tomava se quer um anador pra dor de cabeça, hoje em dia tomo um serie de medicamentos, medicamentos fortes, tomo remédio ate pra depressão, eu só durmo a base de remédio pra dormir, se eu não tiver o remédio pra dormir eu não durmo. Eu sofro dentro da minha casa, meu irmãos não me aceitam como eu sou. Eu me sinto excluída. E tudo acabou, acabou minha vida, as pessoas me diminuíram, me excluem." (ENTREVISTADA 06)

"As pessoas desprezam a gente, é difícil, muito difícil, falam pelas costas, as pessoas se faz de amigo e por trás tão cortando, é difícil, o preconceito é terrível. Eu namoro né? E tudo, só que eu não falo pra pessoa que eu tenho a doença, mas eu me previno." (ENTREVISTADA 09)

Percebeu-se durante a leitura das falas das depoentes acima, que muitas resistem em compartilhar o resultado do exame e enfrentam sozinhas muito sofrimento. Pôde-se perceber, ainda, que apesar de bastante divulgadas as formas de transmissão, muitas enfrentam situações de desprezo e discriminação por parte da família e dos amigos, dificultando, ainda mais, a maneira de encarar o convívio social.

Santos, Gomes e Oliveira (2013) comentam em sua pesquisa realizada com 30 mulheres em um hospital municipal público do Rio de Janeiro, que buscou entender o sofrimento e a dificuldade de encontrar sentido a vida perante diagnóstico de 
HIV/AIDS, identificou que sentimento de angústia, tristeza, falta de esperança, rejeição, preconceito e discriminação foram sentimentos evidenciados em sua pesquisa pelas depoentes.

Por outro lado, Sá, Callegari e Pereira (2007) em sua pesquisa realizada com 25 pacientes acompanhados em um serviço de atendimento especializado (SAE) para pessoas vivendo com HIV/AIDS de um hospital filantrópico do estado de Espírito Santo. Buscou desvelar a concepção dos sujeitos acerca da convivência com HIV/AIDS, foi relatado apenas por dois pacientes que após o impacto sofrido com a revelação do diagnóstico, esses pacientes passaram a incorporar a soropositividade como mais uma etapa a ser vivenciada e não como uma alteração importante no modo de vida, passando inclusive a relatar que não sentem nada e que se consideram normais.

$\mathrm{O}$ enfrentamento adequado de uma doença significa adaptação à nova situação. Nos estudos relacionados ao HIV/AIDS, geralmente os pacientes têm dificuldades de adaptação à nova situação de portador do vírus. O tipo de reação da pessoa ao HIV indica sua (in)capacidade de luta contra o mesmo, sendo visivelmente mais forte aquele que consegue exercer suas atividades rotineiras, apesar da existência do vírus no seu organismo, e inevitavelmente mais fraco e passivo aquele que se deixa levar pela progressão inexorável da doença (Gomes et al., 2011).

Apesar dos avanços nas políticas públicas de prevenção e assistência aos portadores de HIV, o enfrentamento da AIDS no Brasil tem que vencer os desafios do preconceito. Acredita-se que ainda existe medo e falta de informação a respeito da doença, mesmo após vários investimentos e campanhas neste sentido. No qual esta questão vai além da informação, exigindo mudanças de visão de mundo, de crenças e de aceitação do outro na sua singularidade e diversidade (Meirelles et al., 2010).

\section{Considerações Finais}

Observou-se que a maioria das mulheres portadoras de HIV/AIDS estudadas apresentavam comportamento sexual inseguro, demonstrado pelo baixo nível de conhecimento acerca das vias de transmissão e das medidas de prevenção. Percebendo-se a necessidade da atuação multiprofissional visando não só a informação sobre a prevenção e transmissão do HIV, mas também a elaboração de programas de educação em saúde, objetivando sensibilizar os indivíduos para adoção de comportamentos sexuais mais seguros, e ainda enfatizando a vulnerabilidade em situações de risco.

A confiança depositada na lealdade do companheiro associa-se a não utilização de prevenção em suas relações, tornando o risco de infectar-se com o HIV real. Os dados mostraram que a manutenção do equilíbrio da relação no contexto familiar depende do comportamento do homem, já que as mulheres, na maioria das vezes, têm a esperança de que seus companheiros sejam suficientemente leais, excluindo, assim, o risco de virem a adquirir alguma doença sexualmente transmissível.

Assim, discutir sobre adoção de medidas protetoras entre casais para que possam diminuir a transmissão sexual do HIV, constitui uma das formas para que as pessoas façam escolhas mais condizentes com a realidade em suas relações sexuais. Verificou-se que as mulheres que convivem com o vírus HIV enfrentaram situações divergentes e conflitantes ao receber o diagnóstico soropositivo para aprender a viver com essa nova realidade.

A importância do papel da família no apoio é fundamental nesse processo por ser a fonte primária no compartilhamento do diagnóstico, no entanto, algumas não recebem o apoio necessário, deixando-as fragilizadas e tornando-as susceptíveis a distúrbios emocionais. Portanto, é importante a existência dos serviços de aconselhamento, onde essas mulheres possam receber orientações sobre a necessidade do tratamento e acompanhamento emocional por uma equipe multiprofissional capacitada que lhes ofereçam uma assistência mais eficaz e humanizada.

Como se pôde perceber na análise de dados, a culpa gerada pela presença da doença em suas vidas pode estar direcionada diretamente a comportamentos adotados por elas anteriormente que contribuíram para sua contaminação, como, 
por exemplo, em razão da promiscuidade e não-uso de preservativos, no entanto, algumas entrevistadas atribuíram a culpa ao parceiro pela aquisição do HIV, sentindo-se angustiadas e com raiva pela contaminação, pela infidelidade e pela falta de respeito do outro, dessa forma vindo a interferir na relação amorosa.

O estudo espera auxiliar na elaboração de estratégias preventivas e de apoio às mulheres portadoras de HIV/AIDS que visem à promoção da saúde física e mental dessas mulheres, assim como a diminuição da condição de vulnerabilidade. Mais do que isso, espera-se que este estudo desperte o interesse de profissionais e pesquisadores da saúde para a necessidade de intervenções que contemplem não só a informação e orientação dessas mulheres, mas também o apoio emocional e acompanhamento por uma equipe multiprofissional.

\section{Referências}

Aboim, S. (2012). Risco e prevenção do HIV/AIDS: uma perspectiva biográfica sobre os comportamentos sexuais em Portugal. Revista Ciência \& Saúde Coletiva,17(1), 99-112.

Agostini, A., Rocha, F., Melo, E. \& Maksudi, I. (2019). A resposta brasileira à epidemia de HIV/AIDS em tempos de crise, Ciênc. saúde coletiva, 24(12).

Almeida, M. R. C. B., Labrocini, L. M. (2007). A trajetória silenciosa de pessoas portadoras do HIV contada pela história oral. Revista Ciência \& Saúde Coletiva, 12 (1), 263- 274

Ayres, J. R. C. M., Segurado, A. A.C., Galano, E., Marques, H. H. S., França, I., Silva, M. H., \& Paiva, V. (2004). Adolescentes e jovens vivendo com HIV/AIDS: cuidado e promoção da saúde multiprofissional. Enhancing Care Initiative.

Barbosa, K. S., \& Ramalho, M. N. (2007, agosto). A influência do diagnóstico positivo na vida das mulheres contaminadas pelo HIV/AIDS. III Jornada Internacional de Políticas Públicas, São Luís, MA, Brasil. http://www.joinpp.ufma.br/jornadas/joinppIII/html/Trabalhos/EixoTematicoD /e4585e33180269c5226 1KALIANE\%20BARBOSA_MA.\%20NOALDA\%20RAMALHO.pdf

Bardin, L. (2011). Análise de conteúdo (3a ed.). Almedina

Batista, C. B. \& Silva, L. R. (2007). Sentimentos de mulheres soropositivas para HIV diante da impossibilidade de amamentar. Escola Anna Nery Revista de Enfermagem, $11(2), 268-275$.

Cechim, P. L. \& Selli, L. (2007). Mulheres com HIV/AIDS: fragmentos de sua face oculta. Revista Brasileira de Enfermagem, 60 (2),145- 149.

Collins, G. R. (1905). Aconselhamento cristão. Vida nova.

Dyniewicz, A. M. (2007). Metodologia da pesquisa em saúde para iniciantes. Difusão Editora.

Gil, A.C. (2010). Como elaborar projetos de pesquisa (5a ed.). Atlas.

Gil, A.C. (2006). Métodos e Técnicas de Pesquisa Social (6a ed.). Atlas.

Gir, E., Canini, R. M. S. S., Prado, M. A., Carvalho, M. J., Duarte, G. \& Reis R. K. (2004). A feminização da AIDS: conhecimento de mulheres soropositivas sobre a transmissão e prevenção do HIV-1. DST-Jornal brasileiro de Doenças Sexualmente Transmissíveis, 16 (3), $73-76$.

Gomes, A. M. T., Silva, E. M. P., \& Oliveira, D. N. (2011). Representações sociais da AIDS para pessoas que vivem com HIV e suas interfaces cotidianas. Revista Latino-Americana de Enfermagem, 19 (3).

Gomes, R. R. F. M., Cecccato, M. G. B., Rocha, G. M., \& Guimarães, M. D. C. (2013). Conhecimento sobre HIV/AIDS e fatores associados entre homens que fazem sexo com homens em Belo Horizonte, MG. Revista Médica de Minas Gerais, 23 (4), $427-436$.

Guimarães, M. D. C., Magno, L., Ceccato, M. D. G. B., Gomes, R. R. D. F. M., Leal, A. F., Knauth, D. R., \& Kell, L. R. F. S. (2019). HIV/AIDS knowledge among MSM in Brazil: a challenge for public policies. Revista Brasileira de Epidemiologia, 22 (1).

Instituto brasileiro de Geografia e Estatística (IBGE) (2012). População no último censo: IBGE, Censo Demográfico 2010. IBGE. Recuperado de https://cidades.ibge.gov.br/brasil/pi/parnaiba/panorama

Lourenço, S. R. P. N., Afonso, H. G. M. (2009). VIH no feminino: vivência psicológica. Revista Brasileira de Enfermagem, 62 (1), $119-124$.

Meirelles, B. H. S., Silva, D. M. G. V., Vieira, F. M. A., Souza, S. S., Coelho, I. Z., \& Batista, R. (2010). Percepções da qualidade de vida de pessoas com HIV/AIDS. Revista da Rede de Enfermagem do Nordeste, 11(3), 68-76.

Minayo, M. C. S. (2007). Pesquisa social: teoria, método e criatividade (25a ed.). Vozes.

Moreno, D. M. F. C., Reis, A. O. A. (2013). Revelação do Diagnóstico da Infecção pelo HIV no Contexto do Aconselhamento: A Versão do Usuário. Temas em Psicologia, 21(3), 591-609.

Nascimento, I. G. M. S. C., Silva, L. W. S., Martins, L. A., Nunes, E. C. D. A, Cerqueira, D. S. (2010). Estigmas e preconceitos no viver-conviver com HIV/AIDS: um olhar sobre o estado da arte. Revista Integrativa em inovação tecnológica nas ciências e Saúde-REVISE, 1(1),13-19. 
Research, Society and Development, v. 10, n. 7, e53610716683, 2021

(CC BY 4.0) | ISSN 2525-3409 | DOI: http://dx.doi.org/10.33448/rsd-v10i7.16683

Oltramari, L. C., Otto, L.S. (2006). Conjugalidade e Aids: Um estudo sobre infecção entre casais. Psicologia \& Sociedade, 18 (3), 55-61.

Rabuske, M. M. (2009). Comunicação de diagnósticos de soropositividade para o HIV e de AIDS para adolescentes e adultos: implicações psicológicas e repercussões nas relações familiares e sociais (Tese de doutorado). Universidade Federal de Santa Catarina, Florianópolis, SC Brasil. Recuperado de https://repositorio.ufsc.br/xmlui/bitstream/handle/123456789/92396/273205.pdf?sequence=1\&isAllowed=y

Resolução $n^{\circ}$ 466, de 12 de dezembro de 2012. O Plenário do Conselho Nacional de Saúde em sua $240^{\mathrm{a}}$ Reunião Ordinária, realizada nos dias 11 e 12 de dezembro de 2012 , no uso de suas competências regimentais e atribuições conferidas pela Lei $\mathrm{n}^{\circ}$ 8.080, de 19 de setembro de 1990 , e pela Lei $\mathrm{n}^{\circ} 8.142$, de 28 de dezembro de 1990, e considerando o respeito pela dignidade humana e pela especial proteção devida aos participantes das pesquisas científicas envolvendo seres humanos. Recuperado de https://bvsms.saude.gov.br/bvs/saudelegis/cns/2013/res0466_12_12_2012.html

Carvalho, G. S. (2008). Pessoas vivendo com HIV/AIDS: vivências do tratamento anti-retroviral (Dissertação de mestrado). Universidade Estadual de Londrina, Londrina, PR, Brasil. http://www.uel.br/pos/saudecoletiva/Mestrado/diss/97.pdf

Sá, A. M. S., Callegari, F. M., Pereira, E. T. (2007). Conviver com HIV/AIDS: concepções de pessoas com idade acima de 50 anos. Ser Social, $21,259-284$.

Santos, C. C. E., Gomes, A. M. T., \& Oliveira, D. C. (2013). A espiritualidade de pessoas com HIV/AIDS: um estudo de representações sociais. Revista de Enfermagem Referência, (10),15-24.

Serra, A., Sardinha, A. H. L., Pereira, A. N. S., \& Lima, S. C. V. S. (2013). Percepção de vida dos idosos portadores do HIV/AIDS atendidos em centro de referência estadual. Revista Saúde em Debate, 37 (97), 294-304.

Sousa, L. B. \& Barroso, M. G. T. (2009). DST no âmbito da relação estável: análise cultural com base na perspectiva da mulher. Escola Anna Nery Revista de Enfermagem, 13 (1),123-130. 